\title{
Theoretical Review of Boredom and Ways to Eliminate
}

\author{
Kanchi.Madhavi ${ }^{1}$
}

\begin{abstract}
:
Boredom is frequently considered inconsequential and has received relatively little research attention. We argue that boredom has important implications for human functioning, based on emotion theory and empirical evidence. Specifically, we argue that boredom motivates pursuit of new goals when the previous goal is no longer beneficial. Exploring alternate goals and experiences allows the attainment of goals that might be missed if people fail to reengage. Similar to other discrete emotions, we propose that boredom has specific and unique impacts on behavior, cognition, experience and physiology. Consistent with a broader argument that boredom encourages the behavioral pursuit of alternative goals, we argue that, while bored, attention to the current task is reduced, the experience of boredom is negative and aversive, and that boredom increases autonomic arousal to ready the pursuit of alternatives. By motivating desire for change from the current state, boredom increases opportunities to attain social, cognitive, emotional and experiential stimulation that could have been missed. We review the limited extant literature to support these claims, and call for more experimental boredom research.
\end{abstract}

Keywords: Review, Boredom, Eliminate

Boredom is subjective and elusive experience which everyone in their life feels it, it may be transient or chronic manner, but based on personality structures.

Usually boredom is taken granted as it is common experience, it has many faces can result in harmful stress that can lead to disease and accidents. Even though it is uncomfortable feeling, there is general acceptance of its presence.

BERGLER suggest that boredom is an emotional experience that tends to threaten the psychic balance of the individual. Most people suffer boredom silently: it is by their hectic and almost futile search for "fun" that they portray its presence.

Boredom is an affective mental state primarily caused by prolonged exposure to dull, uninteresting or monotonous stimuli.

Some definitions related to boredom

Boredom: an affective mental state primarily caused by prolonged exposure to monotonous stimulation.

Monotony: tedious uniformity or lack of variety.

${ }^{1}$ Lecturer, Department of Psychology, College of social sciences and humanities, ADIGRAT University, Adigrat, Ethiopia.

(C) 2015 I K Madhavi; licensee IJIP. This is an Open Access Research distributed under the terms of the Creative Commons Attribution License (http://creativecommons.org/licenses/by/2.0), which permits unrestricted use, distribution, and reproduction in any Medium, provided the original work is properly cited. 
Apathy: lack of interest or concern.

Emptiness: lack of feelings.

Sensory deprivation: removal or minimization of sensory stimulation.

Tedium: disgust or weariness.

Ennui: feeling of mental weariness produced by lack of interest in surroundings.

\section{Types of boredom:}

There are mainly two types of boredom:

1. Normal boredom

2. Pathological boredom

Another classification of boredom as per the modern psychologists:

1. Apathetic boredom: Repression of forbidden instincts and a decreased imagination

2. Agitated boredom: Secondary state caused by failure of available activities to gratify wishes and fantasies

3. Responsive boredom: Inevitable reaction to a monotonous task or life situation

4. Chronic boredom: Occurs from extraneous multiple factors

5. Interpersonal boredom: Occurs when other people are present

Harlow Shapley placed boredom as the third in a list of five possible causes of world destruction. Gosline reports "boredom is not a unified concept but rather comes in many flavors".

According to OTTO FENICHEL ' BOREDOM is a feeling of displeasure due to a conflict between a need for intensive psychological activity and lack of stimulation or inability to be stimulated thereto'. The displeasurable experience of a lack of impulse. Everyone ought to expect displeasurabledrive tensions and pleasurable drive gratifications. It is also presented in another way like "displeasurable impulses and pleasurable lack of impulses, the displeasurable lack of impulse is BOREDOM".

Boredom is not only lack of impulses it is also need for intensive psychic activity and freedom from tension.

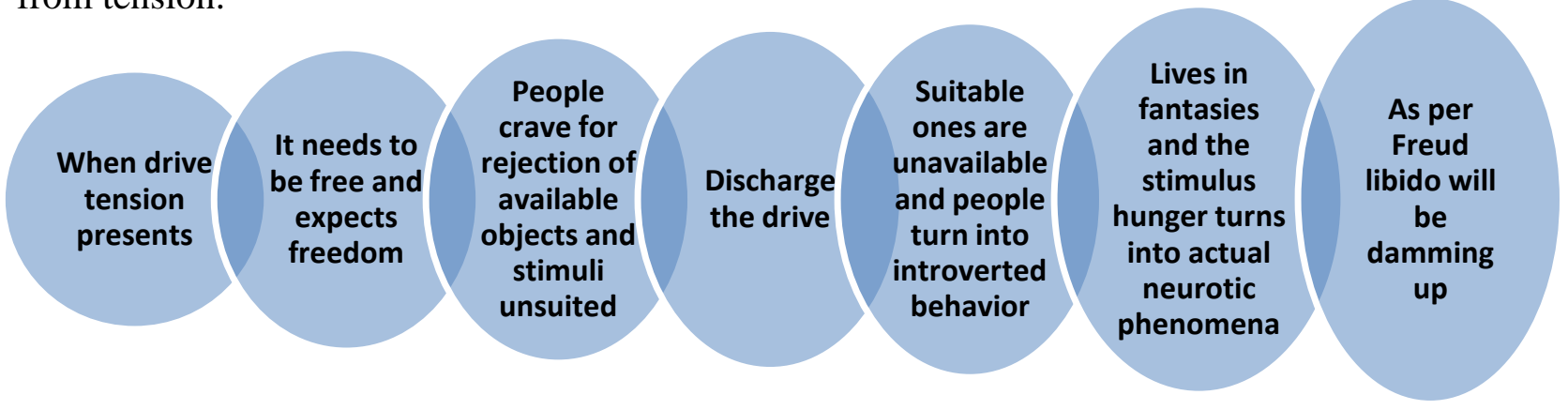

In boredom, drive tension appears but aim is missing and the aim is repressed. As usual the person is turned to external world but he cannot be stimulated. Drive demand conflict exists due to the inability to become stimulated. Psycho-dynamically, ID want drive action external world to substitute, but EGO does not want to substitute but it wants to divert or distract the individual. Theories related to boredom: 


\section{Biological theory:}

Boredom is inattention, and disinterest in environment stimulus.

Inattention as a consequence develops boredom which is related to physical maturation i.e., cortical maturation and myelination of certain nerve fibers in not completed until 12 years. Other biological theories link with boredom are with decreased heart rate and increased erratic heart rate, and also associated with personal life, occupation and attitude.

\section{Psychoanalytical theory:}

In general boredom is perceived as a complicated, internal and affective experience that results in the clients disinterest in the environment.

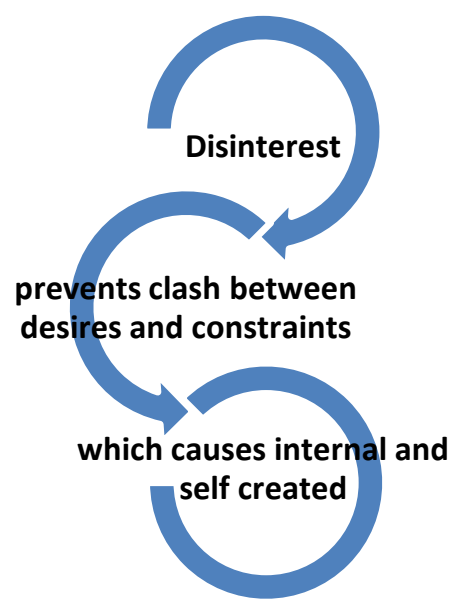

Fenichel believed that bored clients relate originally to a lack of empathic mothering. People frequently relieved bored feelings by oral activities such as eating, drinking and smoking.

Bored clients with Narcissistic Needs- express vague complaints, feelings of emptiness and lack of imitativeness.

Bored clients with Oral Sadistic Needs- abuse substances and other mouth ingested items. Behavioral theory:

Behaviorist believed boredom is caused by client's environment. Boredom is a unique psychophysiological state which is unusual emotional response to predictability. When predictability is too much it causes boredom, if it is too little it causes confusion. Because of boredom task performance is impaired and also perceptions altered, which leads to accidents or injuries. So, it is necessary to maintain optimal level of prediction.

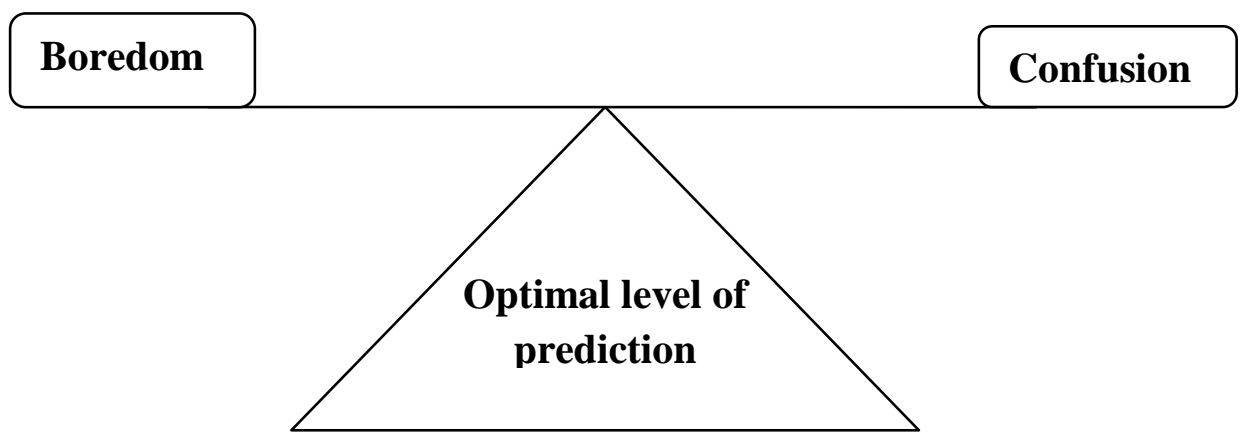


Some bored clients find a reward in boredom. When they are bored they focus on the past and the familiar. By choosing known over the unknown, they avoid undesired emotions.

\section{Cognitive theory:}

Cognitive theories believe that lack of attention is a factor for development of boredom.

Parkinand Hillfound that a person could initially be interested in the task only to become bored later because of his own perceptions and response to the situation.

\section{Sociocultural theory:}

Boredom is caused less by personality traits that by the various situations in which people find themselves. During social upheavals boredom and apathy are caused. Sociologist linked boredom with physical diseases, cruelty and nihilism.

According to Bertrand Russell (1930) boredom "-at least half the sins of the mankind are caused by the fear of it".

\section{How boredom can be eliminated:}

Figure out what you really want to do - Boredom often masks a problem where you want to do a particular activity but something is preventing you. This could happen when you want to watch your favorite television show, but the cable is out. When this happens, the first step to killing boredom is to simply recognize the activity that you truly want to be doing.

Nuke procrastination - Procrastination can cause boredom if there aren't any distractions available to take your mind off your task. If this is the case to eliminate the wait and get busy again.

Get your compass straight - Boredom can just as easily be caused by a lack of direction. Spend a few minutes identifying your goals, desires or passions. Sometimes simply bringing up these can get you motivated again.

Socialize - Get out and meet some friends, or make some new friends. Boredom can often disguise a lack of social energy. Even if you can't see how to meet new people in your area and your friends are busy, go to an online forum that shares one of your interests or pick up a phone. Put off your boredom - Take a look at your to-do list. Commit to doing just one tiny task on that list before you find something fun to do. Often putting off your boredom for a few minutes by being productive can kick the feeling.

Learn something new - Perhaps what you need is some mental stimulation. Here are some fast things you can do to start learning something new:

- Read a book

- Research a topic you're interested in online

- Write a short story

- Pull up Photoshop and practice your artistic skills.

Cut off distractions - Boredom can happen when you are doing a low value task, like random internet surfing or watching television shows that don't interest you. Distractions can be a black hole, sucking you into a prolonged state of disinterest. Turn off the television or computer and start moving around until you find something better to occupy you. 
Fill schedule holes - Too much time is often worse than no time at all. It can be difficult to adjust to the boredom when you suddenly have a schedule vacuum. So many often find themselves getting irritated during holiday periods where their normally busy schedule empties. Spend a few minutes to fill schedule holes to prevent boredom in the first place.

Become your own cheerleader - Take some time to review your wins and high points so that you can restore some confidence and keep moving.

Meditate - This has become everyone's default activity in cases of extreme boredom.

Journal - Open up a word document and just start writing. This works similarly to meditation, although it is a bit more active and less imaginative.

Add a new challenge - If you find yourself consistently bored, this usually means you have a section of time where you don't have an activity that meets your needs. Add a new goal, challenge or hobby to fill up the time.

\section{REFERENCES:}

Bargdill RW A phenomenological investigation of being bored with life. Psychol Rep. 2000 Apr;86(2):493-4.

Bench SW, Lench HC. On the function of boredom. BehavSci (Basel). 2013 Aug 15;3(3):45972 .

Esman AH. Some reflections on boredom. J Am Psychoanal Assoc. 1979;27(2):423-39

Harju L, Hakanen JJ, Schaufeli WB. Job boredom and its correlates in 87 Finnish organizations.J Occup Environ Med. 2014 Sep;56 (9):911-8.

Van Hooff ML, Van Hooft EA. Boredom at work: proximal and distal consequences of affective work-related boredom. J Occup Health Psychol. 2014 Jul;19(3):348-59.

http://www.ncbi.nlm.nih.gov/pubmed

https://www.google.co.in/\#q=boredom

http://99u.com/articles/7188/why-boredom-is-good-for-your-creativity 